\title{
Lower Pregnancy Losses in Lactating Dairy Cows Fed a Diet Enriched in $\alpha$-Linolenic Acid
}

\author{
D. J. Ambrose, ${ }^{\star 1}$ J. P. Kastelic, $†$ R. Corbett, ${ }^{\star}$ P. A. Pitney, ${ }^{*}$ H. V. Petit,ł J. A. Small,§ and P. Zalkovic* \\ *Dairy Research and Technology Centre, Alberta Agriculture Food and Rural Development/University of Alberta, Edmonton T6H 5T6, Canada \\ †Agriculture and Agri-Food Canada, Lethbridge Research Centre, Lethbridge, Alberta, T1J 4B1, Canada \\ $\ddagger$ Agriculture and Agri-Food Canada, Dairy and Swine Research and Development Centre, Lennoxville, Quebec, J1M 1Z3, Canada \\ $\S A g r i c u l t u r e$ and Agri-Food Canada, Brandon Research Centre, Brandon, Manitoba, R7A 5Y3, Canada
}

\begin{abstract}
The objectives were to determine if a diet enriched in $\alpha$-linolenic acid (ALA) would influence ovarian function, early embryo survival, conception rates, and pregnancy losses in lactating dairy cows. Beginning $28 \mathrm{~d}$ before breeding, Holstein cows ( $55 \pm 22 \mathrm{~d}$ postpartum; mean $\pm \mathrm{SD}$ ) were assigned to diets supplemented with either rolled flaxseed (FLAX; 56.7\% ALA, $\mathrm{n}=62$ ) or rolled sunflower seed (SUNF; 0.1\% ALA, $\mathrm{n}=59$ ) to provide approximately $750 \mathrm{~g}$ of oil/d. Diets continued for $32 \mathrm{~d}$ after timed artificial insemination (TAI, d 0) following a Presynch/Ovsynch protocol. Barley silage- and barley grain-based TMR were formulated to meet or exceed National Research Council requirements. Metabolizable protein and net energy for lactation concentrations were similar in the 2 diets. Based upon a mean dry matter intake of $22 \mathrm{~kg} / \mathrm{d}$, cows fed FLAX or SUNF consumed $>410 \mathrm{~g}$ or $<1 \mathrm{~g}$ of ALA, respectively. Pregnancy was confirmed by ultrasound $32 \mathrm{~d}$ after TAI. Nonpregnant cows were placed on a second Ovsynch regimen and reinseminated $42 \mathrm{~d}$ after first TAI, and received oilseeds for $32 \mathrm{~d}$ after second TAI. Relative to prediet levels, FLAX increased the ALA content of milk by $187 \%$. Ovarian ultrasonography was performed in 8 cows per diet; the mean diameter of ovulatory follicles was larger in cows fed FLAX compared with SUNF $(16.9 \pm 0.9$ vs. $14.1 \pm 0.9 \mathrm{~mm})$, but follicle number, corpus luteum size, and plasma progesterone concentrations remained unaffected. Presumptive conception (progesterone $<1 \mathrm{ng} / \mathrm{mL}$ on d 0 and $>1 \mathrm{ng} / \mathrm{mL}$ on $\mathrm{d} 21$ ) rates to first TAI were greater in FLAX than in SUNF (72.6 vs. $47.5 \%)$. Pregnancy losses were lower in cows fed FLAX (9.8\%) compared with those fed SUNF (27.3\%). Including flaxseed in the ration of dairy cows increased the size of the ovulatory follicle and reduced pregnancy losses.
\end{abstract}

Received November 1, 2005.

Accepted March 1, 2006.

${ }^{1}$ Corresponding author: divakar.ambrose@gov.ab.ca
Key words: flaxseed, $\alpha$-linolenic acid, conception rate, pregnancy loss

\section{INTRODUCTION}

Reproductive inefficiency is a major economic problem in dairy production, particularly during the phase of negative energy balance that occurs in early lactation. One way of improving energy status, and thereby reproductive performance, is to increase the energy density of the diet with fat supplementation. Reproductive performance is enhanced by dietary fat independent of energy status (Staples et al., 1998). In that regard, it has been hypothesized that dietary long-chain fatty acids (LCFA), particularly polyunsaturated fatty acids (PUFA), may improve reproductive performance of dairy cattle. Flaxseed is an excellent source of fat and PUFA, but it is not commonly fed to cattle. Previous studies have shown that 2 unique fatty acids, eicosapentaenoic acid (EPA, C20:5n-3) and docosahexaenoic acid (DHA, C22:6n-3), present in substantial concentrations in fish oil, escape biohydrogenation in the rumen $(\mathrm{Gu}-$ lati et al., 1999), reduce $\mathrm{PGF}_{2 \alpha}$ synthesis in the endometrium (Thatcher et al., 1997), delay luteolysis, and improve pregnancy rates (Burke et al., 1997) in lactating dairy cows. Alpha-linolenic acid (ALA, C18:3n-3), a precursor to the fatty acids EPA and DHA, is a major component of flaxseed oil. Feeding whole or processed flaxseed or infusing flaxseed oil into the abomasum of dairy cows increased LCFA concentration in milk (Kennelly and Khorasani, 1993), including that of EPA (Hagemeister et al., 1991). In one study, 30 dairy cows were inseminated after feeding a formaldehyde-treated, flaxseed-based diet or a control diet containing calcium salts of palm oil; conception rates were higher in cows given flaxseed compared with those given the control $\operatorname{diet}$ (88 vs. 50\%; Petit et al., 2001). Studies with larger numbers of cows are needed to determine if these findings are repeatable.

We hypothesized that the high ALA content of flaxseed would improve reproduction by enhancing ovarian function, embryonic development, or both. The objec- 
tives were 1) to determine if a diet supplemented with flaxseed influenced ovarian function; and 2) to compare early embryo survival, conception rates, and pregnancy losses in dairy cows receiving a diet enriched in ALA vs. a control diet (very low in ALA). We also determined the effects of diets on milk yield, milk composition, milk fatty acid profiles, and on plasma concentrations of cholesterol, glucose, NEFA, and triglycerides.

\section{MATERIALS AND METHODS}

\section{Location and Animals}

This study was conducted at the dairy research unit of the University of Alberta, Edmonton, Alberta, Canada $\left(53^{\circ} 34^{\prime} \mathrm{N}, 113^{\circ} 31^{\prime} \mathrm{W}\right)$. Cows were cared for according to the Canadian Council of Animal Care Guidelines (Olfert et al., 1993); all experimental procedures were approved by the Faculty Animal Policy and Welfare Committee, University of Alberta. Cows were housed and fed individually in a tie-stall barn equipped with an in-stall pipeline milking system. Cows were milked twice daily at 0430 and $1600 \mathrm{~h}$ and let out for exercise in a dirt-based covered area twice daily, for approximately $1 \mathrm{~h}$ each time. Cows were weighed monthly and body condition was scored once every 3 wk using a 5point scale $(1=$ emaciated, and $5=$ obese; Wildman et al., 1982).

\section{Experimental Diets}

Lactating, nonpregnant dairy cows $(\mathrm{n}=121)$ with no overt clinical illnesses were randomly assigned to 1 of 2 dietary treatments starting $55 \pm 22 \mathrm{~d}$ (mean \pm SD) after calving. Rations were formulated to meet or exceed the requirements of a $650-\mathrm{kg}$ cow at 50 DIM, producing $45 \mathrm{~kg} / \mathrm{d}$ of milk with $3.5 \%$ fat (NRC, 2001). Diet composition and chemical analysis of the TMR are presented in Table 1. Diets were isocaloric and provided equal amounts of MP. Dry matter, protein, fat, and fatty acid content of the oilseeds are presented in Table 2 . The concentrate mixtures were formulated to provide approximately $750 \mathrm{~g}$ of oil/d per cow from either rolled flaxseed (FLAX) or rolled sunflower seed (SUNF). Flaxseed and sunflower seed were processed in a roller mill (Lethbridge Industries Ltd., Lethbridge, AB, Canada) equipped with rollers that were $22.9 \mathrm{~cm}$ in diameter and $76.2 \mathrm{~cm}$ long, with 12 grooves per $2.54 \mathrm{~cm}$. The rollers were adjusted to provide the coarsest roll possible, while ensuring that the seed coat was broken. Cows received their respective diets for at least $8 \mathrm{wk}$. Diets were delivered individually, once daily at $1000 \mathrm{~h}$, with a self-propelled machine that mixed, weighed and dispensed rations (Data Ranger; American Calan Inc.,
Table 1. Ingredients and chemical composition of the experimental diets fed to dairy cows

\begin{tabular}{lcc}
\hline & Sunflower & \\
Item & seed & Flaxseed \\
\hline Ingredients, \% of DM & & \\
Alfalfa hay, chopped & 8.0 & 8.1 \\
Alfalfa silage & 25.3 & 25.1 \\
Barley silage & 8.0 & 8.1 \\
Barley grain, dry rolled & 16.1 & 16.4 \\
Corn grain, ground & 6.4 & 6.5 \\
Molasses, beet & 0.6 & 0.6 \\
Corn gluten meal, dried & 4.6 & 4.7 \\
Soybean meal, solvent 48\% CP & 1.1 & 0 \\
Sunflower seed, rolled & 8.7 & 0 \\
Flaxseed, rolled & 0 & 9.0 \\
Dried corn distillers grains with solubles & 19.3 & 19.6 \\
Minerals/vitamin premix & 2.0 & 2.0 \\
Composition, chemical analysis ${ }^{1}$ & & \\
CP, \% of DM & 23.6 & 22.6 \\
NE ${ }_{\text {, }}$ Mcal/kg of DM & 1.72 & 1.72 \\
ADF, \% of DM & 21.7 & 20.6 \\
NDF, \% of DM & 32.6 & 32.7 \\
Crude fat, \% of DM & 7.15 & 7.23 \\
Crude fat, added, \% of DM & 3.36 & 3.21 \\
\hline
\end{tabular}

${ }^{1}$ Nutrient content of the TMR was calculated from chemical analyses of the forages and the oilseed concentrate mixtures; ADF and $\mathrm{NDF}$ of the concentrate mixtures were calculated using the chemical analyses provided in NRC (2001).

${ }^{2}$ Calculated using published values of feed ingredients (NRC, 2001).

Northwood, NH). To determine daily intake, orts were weighed before commencement of each feeding.

\section{Ovarian Ultrasonography}

Transrectal ultrasonography (Aloka-500V scanner with 7.5-MHz linear transducer, Aloka Co., Tokyo, Japan) was performed in a subset of 16 cows ( $n=8$ per diet) on alternate days, from d 0 to 21 (d $0=$ day of insemination), to monitor ovarian follicular dynamics

Table 2. Dry matter, protein, and fat content, and fatty acid methyl esters present in oilseed

\begin{tabular}{lcc}
\hline & Flaxseed & $\begin{array}{l}\text { Sunflower } \\
\text { seed }\end{array}$ \\
\hline DM, \% & 94.7 & 94.6 \\
CP, \% & 23.4 & 15.8 \\
Crude fat, \% of DM & 35.7 & 38.8 \\
Fatty acid, \% of total lipid & & \\
C16:0 & $5.8^{\mathrm{a}}$ & $7.0^{\mathrm{b}}$ \\
C18:0 & $3.7^{\mathrm{a}}$ & $5.0^{\mathrm{b}}$ \\
C18:1 & $16.7^{\mathrm{a}}$ & $12.2^{\mathrm{b}}$ \\
C18:2 & $16.5^{\mathrm{a}}$ & $74.1^{\mathrm{b}}$ \\
C18:3 & $56.7^{\mathrm{a}}$ & $0.12^{\mathrm{b}}$ \\
C20:0 & $0.18^{\mathrm{a}}$ & $0.57^{\mathrm{b}}$ \\
C20:3 & $0.13^{\mathrm{a}}$ & $0.75^{\mathrm{b}}$ \\
C20:1 & $0.22^{\mathrm{a}}$ & $0.12^{\mathrm{b}}$ \\
C24:0 & $0.09^{\mathrm{a}}$ & $0.21^{\mathrm{b}}$ \\
\hline
\end{tabular}

${ }^{\mathrm{a}, \mathrm{b}}$ Means within the same row followed by different superscripts differ $(P<0.002)$. 
(Kassa et al., 2002). The number of class 1 ( $<6 \mathrm{~mm}$ ), class 2 (6 to $9 \mathrm{~mm}$ ), and class $3(>9 \mathrm{~mm}$ ) follicles located in each ovary was recorded. The relative locations of class 2 and class 3 follicles, and the diameter of the dominant follicle(s), were also recorded at each examination. The size of the corpus luteum was determined using built-in calipers, and recorded.

\section{Collection of Milk and Blood Samples}

Milk samples (for fatty acid analysis) were obtained from 8 cows of each dietary group 1 wk before (wk 0) and $4 \mathrm{wk}$ after the initiation of diets. Samples were collected at 2 consecutive milkings, mixed in proportion to yield to obtain a composite sample, and stored at $-20^{\circ} \mathrm{C}$ until processed for fatty acid analysis.

Blood samples were collected from these 16 cows on $\mathrm{d}-10,-3$, daily from $\mathrm{d} 0$ to 7 , and on $\mathrm{d} 14,16,18$, 21 , and 24 to determine progesterone concentrations in plasma. Additional blood samples were collected from cows at 14-d intervals for $6 \mathrm{wk}$, starting on the day of initiation of diets $(4$ samples per cow at $0,2,4$, and 6 wk after start of diets) to determine plasma concentrations of cholesterol, glucose, NEFA, and triglycerides. Blood samples were collected from all remaining cows on $\mathrm{d}-10,-3,0,21$, and 24 for determination of plasma progesterone concentrations. Blood samples were obtained on $\mathrm{d} 7$ from 92 of the 121 cows. All blood samples ( 7 to $10 \mathrm{~mL}$ ) were collected by coccygeal venipuncture into evacuated tubes (Vacutainer, Becton Dickinson and Co., Franklin Lakes, NJ) containing sodium heparin and were chilled immediately after collection, and centrifuged $(1,500 \times g, 20 \mathrm{~min})$ within $2 \mathrm{~h}$; plasma was harvested, and stored at $-20^{\circ} \mathrm{C}$ until further processing.

\section{Reproductive Management}

To eliminate the variations associated with estrus detection, and for managerial convenience, timed artificial insemination (TAI) was performed on all cows following a protocol for synchronization of ovulation (Ovsynch; Pursley et al., 1995). Ovarian status was presynchronized by 2 injections of $\mathrm{PGF}_{2 \alpha}(500 \mu \mathrm{g}$ of cloprostenol; Estrumate, Schering Canada Inc., Pointe Claire, QC, Canada) given $14 \mathrm{~d}$ apart, and the Ovsynch protocol was initiated $12 \mathrm{~d}$ after the second of the 2 presynchronizing $\mathrm{PGF}_{2 \alpha}$ treatments. The Ovsynch protocol involved $2 \mathrm{GnRH}$ treatments (gonadorelin acetate, $100 \mu \mathrm{g}$; Fertiline, Vetoquinol NA Inc., Lavaltrie, QC, Canada) given $9 \mathrm{~d}$ apart with a $\mathrm{PGF}_{2 \alpha}$ treatment given $7 \mathrm{~d}$ after the first GnRH treatment. Cows were TAI approximately $16 \mathrm{~h}$ after the second $\mathrm{GnRH}$ treatment.

Presumptive conception rate at $\mathrm{d} 24$ was assessed based on plasma progesterone concentrations at 0,21 , and $24 \mathrm{~d}$ after TAI. Cows were presumed conceived on d 24 only if the progesterone concentration was $<1 \mathrm{ng} /$ $\mathrm{mL}$ on $\mathrm{d} 0$ and $\geq 1 \mathrm{ng} / \mathrm{mL}$ on both $\mathrm{d} 21$ and 24 . Pregnancy diagnosis was performed by transrectal ultrasonography $32 \mathrm{~d}$ after TAI, and reconfirmed by transrectal palpation of uterine contents approximately $90 \mathrm{~d}$ after TAI. Cows were monitored for return to estrus and bred again if detected in estrus. Once pregnancy was confirmed at $32 \mathrm{~d}$, pregnant cows were removed from the experimental diets. Nonpregnant cows were immediately placed on the Ovsynch protocol for a second time, and rebred by TAI $10 \mathrm{~d}$ later ( $42 \mathrm{~d}$ after the first TAI). In these cows, the experimental diets continued until pregnancy diagnosis, $32 \mathrm{~d}$ after second TAI.

Cows with progesterone concentrations $<1 \mathrm{ng} / \mathrm{mL}$ on $\mathrm{d}-10,-3$, and 0 were considered anestrous. Cows with progesterone concentrations $\geq 1 \mathrm{ng} / \mathrm{mL}$ on $\mathrm{d}-3$ and $<1$ $\mathrm{ng} / \mathrm{mL}$ on $\mathrm{d} 0$ were considered responders to the synchronization treatment. When $\mathrm{d} 7$ samples were available $(n=92)$, the progesterone concentrations of $d 7(\geq 1$ $\mathrm{ng} / \mathrm{mL}$ ) were considered in addition to that of $\mathrm{d}-3$ and 0 (as described above), for determining the response to synchronization treatment.

\section{Analyses of Feed, Milk, and Plasma}

Feed samples were dried at $60^{\circ} \mathrm{C}$ for $72 \mathrm{~h}$, and ground through a 1-mm screen (Thomas-Wiley mill, model 4; Thomas Scientific, Swedesboro, NJ). Samples were analyzed for $\mathrm{CP}(6.25 \times \mathrm{N}$; Leco FP-428 nitrogen determinator, Leco Corp., St. Joseph, MI), NDF, and ADF (Ankom filter bag technique, Ankom Company, Macedon, NY). Dry matter was determined by drying samples overnight at $135^{\circ} \mathrm{C}$.

Concentrations of fat and protein in milk were determined using a midinfrared analyzer (Milko Scan 605, A/S N Foss Electric, Hillerød, Denmark) at the Central Milk Testing Laboratory in Edmonton (AB, Canada).

Milk fat extraction and transmethylation were performed according to the procedure of Chouinard et al. (1999) and fatty acid methyl esters were analyzed on a Varian 3600 gas chromatograph (Varian Inc., Palo Alto, CA) equipped with a septum programmable injector and flame-ionization detector. Procedures for fatty acid analysis of oilseeds were as described by Sukhija and Palmquist (1988).

Plasma progesterone concentrations were determined using a solid-phase radioimmunoassay kit (Coata-Count, Diagnostic Products Corporation, Los Angeles, CA). The intra- and interassay coefficients of variation were 5.3 and $8.0 \%$, respectively. Plasma concentrations of glucose, NEFA, triglycerides, and cholesterol were analyzed by photometric methods using a clinical chemistry system (Dade Dimension XL, Dade 
Behring, Inc., Mississauga, ON, Canada) in a commercial laboratory (Central Veterinary Pathology Laboratory Ltd., Edmonton, AB, Canada).

\section{Statistical Analyses}

Data were analyzed with ANOVA for a completely randomized design. Repeated measures on DMI, BCS, BW, ovarian follicles, concentrations of hormones and metabolites in plasma, and that of milk fatty acids were analyzed using the MIXED procedure of SAS (SAS Institute, 2000), with the following model:

$$
Y_{i k j}=\mu+\alpha_{i}+\beta_{j}+(\alpha \beta)_{i j}+e_{i j k}
$$

where $\mu$ is the population mean, $\alpha_{\mathrm{i}}$ is a population parameter corresponding to treatment (diet) $i, \beta_{j}$ is the fixed effect of time $j,(\alpha \beta)_{i j}$ is the effect of treatment by time interaction, and $e_{i j k}$ is the residual error. The Kenward-Roger procedure was used for approximating the degrees of freedom (Kenward and Roger, 1997). Animal nested within treatment was considered as the subject on which repeated measures were taken and covariance structures modeled. Based on the smallest values of fit statistics for Akaike's information criterion, Akaike's information criterion corrected, and Bayesian information criterion, the covariance structure of the repeated measurements for each variable was modeled separately and an appropriate structure fitted (Littell et al., 2000). Variables with only 2 time-point comparisons (wk 0 and 4), such as yields of milk, fat, and protein, and concentrations of fat and protein, were analyzed using a model similar to the one described above, but time and interaction with time were not considered. Preplanned treatment comparisons were made with the PDIFF option and declared significant at $P<0.05$. Categorical data (presumptive conception rate at $24 \mathrm{~d}$ postTAI, actual conception rate at $32 \mathrm{~d}$, estimated embryo survival, proportion of cows calving, and calf sex) were analyzed using a $\chi^{2}$ test. The influence of cow, parity, DIM, BCS, BW, and month of TAI on pregnancy and embryo survival was tested using a linear model procedure. The influence of the above variables on pregnancy was tested using a stepwise regression (forward selection) procedure. Odds ratio estimates for pregnancy risk were computed using the LOGISTIC procedure of SAS (SAS Institute, 2000). To determine if cows were distributed evenly between the 2 dietary groups by parity and DIM, frequency tables were generated, and results analyzed by a $t$-test. For all data, differences were considered significant if a probability value of $\leq 0.05$ was obtained. Probability values of 0.05 to 0.10 were considered as trends.
Table 3. Least squares means of DMI, BW, BCS, milk yield, and milk components in dairy cows fed a TMR that included either rolled flaxseed (FLAX) or rolled sunflower seed (SUNF)

\begin{tabular}{lccc}
\hline Variable & FLAX & SUNF & SEM \\
\hline DMI, kg/d & $22.5^{\mathrm{a}}$ & $21.3^{\mathrm{b}}$ & 0.50 \\
BW, kg & 612.4 & 609.9 & 5.60 \\
BCS & 2.81 & 2.82 & 0.03 \\
Milk yield, kg/d & 36.7 & 36.0 & 0.94 \\
Milk fat, \% & 3.69 & 3.37 & 0.07 \\
Milk fat yield, kg/d & 1.33 & 1.20 & 0.04 \\
Milk protein, \% & 3.01 & 2.97 & 0.08 \\
Milk protein yield, kg/d & 1.09 & 1.06 & 0.04 \\
\hline
\end{tabular}

${ }^{\mathrm{a}, \mathrm{b}}$ Means with different superscripts within the same row tended to differ $(P=0.08)$.

\section{RESULTS}

\section{Intake, BW, and BCS}

Dry matter intake tended $(P=0.08)$ to be lower for cows on SUNF compared with those on FLAX diet. Body weight increased with time $(P<0.01)$, but was similar between diets (Table 3 ). There were no differences in BCS between diets.

\section{Milk Yield, Composition, Fatty Acid Profile, and Plasma Metabolites}

Milk yield and milk protein concentration and yield were not significantly affected by either diet (Table 3) or time. Concentration and yield of milk fat did not change from wk 0 to 4 in cows fed FLAX, whereas milk fat concentration and yield declined from 3.54 to $3.20 \%$ $(P<0.05)$ and from 1.25 to $1.14 \mathrm{~kg} / \mathrm{d}(P<0.05)$, respectively, from wk 0 to 4 in cows fed SUNF.

Dietary treatments had a significant impact on milk fatty acid composition (Table 4). The treatments had a differential effect on short-chain fatty acids in milk; they were reduced $(P<0.05)$ by SUNF, but not by FLAX feeding. In general, both treatments depressed $(P<$ $0.05)$ medium-chain fatty acids and increased LCFA in milk. Of the 18-carbon fatty acids, ALA (18:3) content nearly tripled (187\% increase) with FLAX $(P<0.05)$, and increased by $22 \%$ with SUNF $(P<0.05)$. Linoleic acid (18:2) content was increased by $122 \%$ with SUNF $(P<0.05)$ and by $74 \%$ with FLAX $(P<0.05)$. The proportion of milk 18:2 cis-9, trans-11 (conjugated linoleic acid) doubled with FLAX and tripled with SUNF ( $P$ $<0.01$ ).

Plasma concentrations of glucose, triglycerides, cholesterol, and NEFA did not differ $(P>0.10)$ between diets (Table 5), but glucose concentrations were higher at wk 6 than in earlier weeks in both dietary groups. 
Table 4. Effect of feeding flaxseed (FLAX) or sunflower seed (SUNF) on milk fatty acid (FA) composition in dairy cows ${ }^{1}$

\begin{tabular}{|c|c|c|c|c|c|}
\hline \multirow[b]{2}{*}{ Fatty acids, $\%$ of total } & \multicolumn{2}{|c|}{ FLAX } & \multicolumn{2}{|c|}{ SUNF } & \multirow[b]{2}{*}{ SEM } \\
\hline & Before & After & Before & After & \\
\hline Unsaturated:saturated & $0.53^{\mathrm{a}}$ & $0.70^{\mathrm{b}}$ & $0.58^{\mathrm{c}}$ & $0.88^{\mathrm{d}}$ & 0.03 \\
\hline SCFA $^{2}$ & 7.46 & 6.99 & $6.80^{\mathrm{c}}$ & $5.69^{\mathrm{d}}$ & 0.27 \\
\hline $\mathrm{MCFA}^{3}$ & $46.45^{\mathrm{a}}$ & $37.08^{\mathrm{b}}$ & $44.68^{\mathrm{c}}$ & $34.62^{\mathrm{d}}$ & 0.68 \\
\hline LCFA $^{4}$ & $43.37^{\mathrm{a}}$ & $51.15^{\mathrm{b}}$ & $45.74^{\mathrm{c}}$ & $56.28^{\mathrm{d}}$ & 0.82 \\
\hline Monounsaturated $\mathrm{FA}^{5}$ & $30.98^{\mathrm{a}}$ & $33.89^{\mathrm{b}}$ & $32.84^{\mathrm{c}}$ & $38.77^{\mathrm{d}}$ & 0.94 \\
\hline Polyunsaturated $\mathrm{FA}^{6}$ & $2.74^{\mathrm{a}}$ & $5.27^{\mathrm{b}}$ & $2.77^{\mathrm{c}}$ & $6.25^{\mathrm{d}}$ & 0.15 \\
\hline $\mathrm{C} 18: 2$ & $1.89^{\mathrm{a}}$ & $3.29^{\mathrm{b}}$ & $1.94^{\mathrm{c}}$ & $4.31^{\mathrm{d}}$ & 0.09 \\
\hline C18:2 cis -9, trans -11 & $0.47^{\mathrm{a}}$ & $0.98^{b}$ & $0.43^{\mathrm{c}}$ & $1.43^{\mathrm{d}}$ & 0.06 \\
\hline C18:3n-3 & $0.31^{\mathrm{a}}$ & $0.89^{\mathrm{b}}$ & $0.32^{\mathrm{c}}$ & $0.39^{\mathrm{d}}$ & 0.01 \\
\hline
\end{tabular}

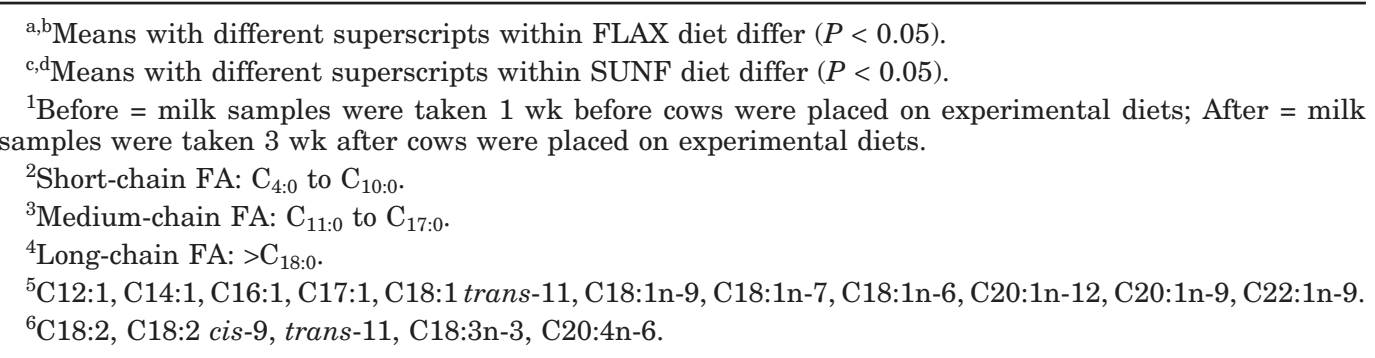

\section{Ovarian Characteristics, and Plasma Progesterone Concentrations}

The ovulatory follicle (before the first AI, d 0) was larger in cows fed FLAX compared with those fed SUNF $(16.9 \pm 0.91$ vs. $14.1 \pm 0.86 \mathrm{~mm} ; P<0.05)$. Mean number of class 1, 2, or 3 follicles, growth rate of nonovulatory dominant follicle, or size of corpus luteum was not affected $(P>0.10)$ by diet (data not shown). There was no effect $(P>0.10)$ of diet, or diet $\times$ day interaction for plasma progesterone concentrations (FLAX $4.52 \pm 0.45$; SUNF $4.13 \pm 0.44 \mathrm{ng} / \mathrm{mL}$ ). Although mean serum progesterone concentrations were not different between diets, mean progesterone concentration was higher at the time of insemination (d 0 ) in cows fed FLAX compared with those fed SUNF $(0.41 \pm 0.06$ vs. $0.15 \pm 0.06$ $\mathrm{ng} / \mathrm{mL} ; P<0.05)$ in the subset of 16 cows.

\section{Conception Rates and Pregnancy Losses}

Presumptive conception rate (d 24) to the first TAI was higher $(P<0.01)$ in cows fed FLAX $(72.6 \%)$ than in those fed SUNF (47.5\%). Actual conception rate (d $32)$ to first TAI tended to be higher $(P<0.07)$ in cows fed FLAX (48.4\%) compared with those fed SUNF $(32.2 \%)$. In the stepwise regression analysis, the overall model accounted for $12.6 \%$ of the variation in pregnancy $(P=0.02)$, with cow, DIM, and parity contributing 9.5 , 1.6 , and $1.5 \%$, respectively. Based on the odds ratio of 0.50 , the pregnancy risk associated with FLAX diet was 2 -fold (1/0.5) higher.

About 12\% (14 of 121) of the cows were anestrous (based on plasma progesterone concentrations); they were equally distributed between the dietary groups. When only the cyclic cows $(\mathrm{n}=107)$ were considered, d 32 conception rates to first TAI tended to increase slightly for FLAX vs. SUNF (53.6 and 37.3\%, respectively; $P<0.09$ ). The synchronization response to the Ovsynch treatment preceding first TAI, as determined by progesterone concentrations, was $83 \%$.

There was, apparently, a higher rate of early ( $\mathrm{d} 0$ to 24) embryo survival in cows fed FLAX compared with those fed SUNF. However, the difference between pre-

Table 5. Effect of feeding flaxseed (FLAX) or sunflower seed (SUNF) on plasma metabolites in dairy cows

\begin{tabular}{lllllrl}
\hline & & & & \multicolumn{3}{c}{$P$-value } \\
\cline { 5 - 7 } & & & & & & \multicolumn{1}{c}{$\begin{array}{c}\text { Diet } \\
\text { Plasma variable }\end{array}$} \\
\cline { 5 - 7 } & FLAX & SUNF & SE & Diet & Week & Week \\
\hline Cholesterol, mmol/L & 6.29 & 5.39 & 0.47 & 0.18 & 0.52 & 0.81 \\
Glucose, $\mathrm{mmol} / \mathrm{L}$ & 2.47 & 2.31 & 0.09 & 0.21 & $<0.01$ & 0.60 \\
NEFA, $\mathrm{mEq} / \mathrm{L}$ & 0.30 & 0.41 & 0.10 & 0.33 & 0.25 & 0.47 \\
Triglycerides, $\mathrm{mmol} / \mathrm{L}$ & 0.15 & 0.16 & 0.01 & 0.80 & 0.31 & 0.55 \\
\hline
\end{tabular}


Table 6. Pregnancy losses, and calving details, in dairy cows fed flaxseed (FLAX) or sunflower seed (SUNF) confirmed pregnant by ultrasonography $32 \mathrm{~d}$ after timed AI

\begin{tabular}{lll}
\hline & \multicolumn{2}{c}{ Dietary treatment } \\
\cline { 2 - 3 } Observation & FLAX, & SUNF, \\
n $(\%)$ & 35 \\
\hline Cows confirmed pregnant (32 d) & 42 & $4 / 35(11.4)$ \\
Early pregnancy loss (32 to 90 d) & $2 / 42(4.8)$ & $2 / 31(6.5)$ \\
Cows sold (after 90 d) & $1 / 40(2.5)$ & $5 / 29(17.2)$ \\
Late pregnancy loss (90 d to term) & $2 / 39(5.1)$ & $9 / 33(27.3)^{\mathrm{b}}$ \\
Overall pregnancy loss (early and late) & $4 / 41(9.8)^{\mathrm{a}}$ & $24 / 33(72.7)^{\mathrm{b}}$ \\
Proportion of cows calving & $37 / 41(90.2)^{\mathrm{a}}$ & 2 \\
Twin calving & 2 & 9 \\
Assisted calving & 11 & 26 \\
Calves born & 39 & $13 / 13$ \\
Male/female ratio & $15 / 24$ & 1 \\
Stillbirths & 1 &
\end{tabular}

${ }^{\mathrm{a}, \mathrm{b}}$ Values within a row with different superscripts differ $(P<0.05)$.

${ }^{1}$ Includes twins and stillborn calves.

sumptive (d 24) and actual (d 32) conception rates indicated that embryo survival rate from d 24 to 32 did not differ between SUNF (67.9\%) and FLAX (66.7\%). Cows were evenly distributed by parity and DIM between dietary groups. Neither parity nor DIM influenced conception rates; however, parity affected embryo survival, with older cows ( $>3$ lactation) having a lower embryo survival rate than younger ( $\leq 3$ lactation) cows (38.6 vs. $83.8 \%, P<0.02$ ). Conception rates to the second TAI (37.5\% for FLAX and $41.0 \%$ for SUNF) and overall pregnancy rates (combined for both TAI; $67.7 \%$ for FLAX and $59.3 \%$ for SUNF) were not different between diets $(P>0.10)$.

Three pregnant cows (1 FLAX, 2 SUNF) left the herd before calving; therefore, calving data were unavailable from these animals. Pregnancy losses were lower $(P<$ 0.05 ) in cows fed FLAX compared with those fed SUNF (Table 6).

\section{DISCUSSION}

Dietary PUFA and their influence on reproductive processes in cattle have been discussed by several authors in recent years (Abayasekara and Wathes, 1999; Thatcher et al., 1997, 2004). In a previous small-scale study (Petit et al., 2001), a flaxseed-based diet increased conception rate in dairy cows compared with control cows fed a diet containing Megalac, a calcium soap of palm oil. Although the diets used in this study and in that of Petit et al. (2001) were not identical, both studies had a similar hypothesis-that the high ALA content of flaxseed would have a positive influence on reproductive function. Sunflower seed was chosen for the control ration in the present study because of its very low ALA content.

\section{Ovarian Function, Conception Rates, and Pregnancy Losses}

Ovulatory follicles were significantly larger in cows of the FLAX group compared with those in the SUNF group, but there were no differences between diets in the number of class 1,2 , or 3 follicles, or in the total number of follicles. Higher fertility was reported in cows ovulating larger follicles even without an increase in progesterone concentrations in the subsequent luteal phase (Peters and Pursley, 2003). Therefore, the ovulation of larger follicles in FLAX cows may have contributed to the improvement in conception rate, perhaps due to a more viable oocyte. As in the present study, Petit et al. (2001) found no dietary effects on the number of class 1, class 2 , or class 3 follicles. In another study (Robinson et al., 2002), the number of medium-sized (class 2 equivalent) follicles increased in cows fed diets enriched in protected ALA and linoleic acid, and the diameter of the first dominant follicle was larger in cows fed linoleic acid, but not in those fed ALA.

The overall plasma progesterone concentrations did not differ between dietary groups in the present study. In contrast, Robinson et al. (2002) reported lower progesterone concentrations in cows fed diets enriched in PUFA (either ALA or linoleic acid). The mean progesterone concentration at TAI (d 0,64 to $68 \mathrm{~h}$ after $\mathrm{PGF}_{2 \alpha}$ treatment) was higher in FLAX $(0.41 \mathrm{ng} / \mathrm{mL})$ than in the SUNF $(0.15 \mathrm{ng} / \mathrm{mL})$ in the subset of 16 cows subjected to intensive ovarian ultrasonography and frequent blood sampling. However, when all cows in the study were considered, there were no differences in plasma progesterone concentrations at $d 0$. Burke et al. (1997) reported significantly higher concentrations of progesterone $2 \mathrm{~d}$ after $\mathrm{PGF}_{2 \alpha}$ injection in cows fed menhaden fish meal, suggesting delayed luteal regres- 
sion in cows consuming the n-3 (omega-3) fatty acids, EPA and DHA. Similarly, supplementation with menhaden fish meal reduced $\mathrm{PGF}_{2 \alpha}$ secretion in dairy cows (Thatcher et al., 1997). Therefore, a diet enriched in ALA (due to the inclusion of flaxseed) can potentially suppress $\mathrm{PGF}_{2 \alpha}$ production, because ALA can be synthesized into EPA and DHA through desaturation and elongation (Abayasekara and Wathes, 1999).

Presumptive conception rate at $24 \mathrm{~d}$ post-TAI and the proportion of pregnancies carried to term were higher in FLAX than in SUNF cows. We recognize that early pregnancy determination (presumptive conception) based on plasma progesterone concentrations has some limitations. However, when progesterone concentrations in 3 (as in the present study) or more samples obtained between $\mathrm{d} 0$ and 24 were considered, the pregnancy prediction was about $90 \%$ accurate (Kaul and Prakash, 1994). Although there was no difference in the embryo survival rate between $d 24$ and 32 postTAI, the numerically increased conception rates in FLAX cows occurred early, apparently through a higher rate of embryonic survival before d 24 (increased presumptive conception rate). These results are consistent with those of Petit et al. (2001), who reported increased conception rates in cows given a ration enriched in ALA by supplementation with formaldehyde-treated flaxseed, compared with cows given a control ration (low in ALA) supplemented with Megalac. In their study, they excluded anestrous or cystic cows from insemination, and cows were inseminated only after detection of standing estrus. In contrast, no cow was excluded, and all cows received TAI without estrous detection in the present study. Furthermore, whereas the first insemination occurred at $83 \mathrm{~d}$ postpartum in the present study, inseminations began much later (at $105 \mathrm{~d}$ ) in the other study (Petit et al., 2001), and continued until all cows were detected in estrus. Lower milk production levels $(19 \mathrm{~kg} / \mathrm{d})$ in cows used by Petit et al. (2001) compared with that ( $36 \mathrm{~kg} / \mathrm{d}$ ) of cows in the present study could have also contributed to the higher fertility. Conception rates in the present study were within the current range reported for lactating Holstein cows managed by TAI in Canada and the United States. In a recent study using 983 beef heifers, Colazo et al. (2004) compared the effects of dietary inclusion of whole flaxseed and whole sunflower seed in a TAI program and found no effect of diets on conception rates. However, the quantity of oilseeds included was considerably lower $(1 \mathrm{~kg} / \mathrm{d})$ than that used in the present study, suggesting that higher levels of supplementation, processing, or both, are necessary to enhance conception rates.

Pregnancy losses were lower in the FLAX group, resulting in a higher proportion of pregnancies carried to term. Even though cows received the experimental diets for only $60 \mathrm{~d}$ (i.e., from $28 \mathrm{~d}$ before TAI to $32 \mathrm{~d}$ after TAI), the ALA-enriched diet during early gestation improved maintenance of pregnancy. These findings could have major implications for nutritional management of reproductive function and warrant further investigation. Because ALA can be transformed to DHA through desaturation and elongation (Abayasekara and Wathes, 1999), it is plausible that there was an increased availability of DHA for transport to the embryo in FLAXfed cows, thus enhancing embryonic development and reducing pregnancy losses. Although this remains a possibility, most of the benefit (in terms of embryo survival) in FLAX cows occurred earlier than $24 \mathrm{~d}$, a period when placental development and attachment have barely begun. Alternatively, enhancement of early embryonic development by the FLAX diet may have occurred through an attenuation of $\mathrm{PGF}_{2 \alpha}$ secretion around the time of maternal recognition of pregnancy, or through other embryotrophic mechanisms. However, these remain speculations at this time.

High conception rates (Tenhagen et al., 2004) and improved pregnancy retention (Starbuck et al., 2004) have been reported in primiparous dairy cows. Parity did not influence conception rate in the present study; however, pregnancy losses were higher in older cows (exceeding 3 lactations) than in younger animals.

\section{Intake, BW, and BCS}

Inclusion of rolled flaxseed at approximately $9 \%$ on a DM basis had no negative effect on intake in the present study. Similarly, inclusion of whole flaxseed at levels of 5 to $15 \%$ (Kennelly and Khorasani, 1993) or feeding formaldehyde-treated flaxseed at up to $17 \%$ of DM (Petit et al., 2001) did not reduce DMI in dairy cows. In the present study, DMI was slightly reduced in SUNF cows, which is in agreement with the observation of Petit (2003), who found lower DMI in cows fed sunflower seed compared with those fed either whole untreated or whole formaldehyde-treated flaxseed.

\section{Milk Yield and Milk Composition}

Milk yield did not differ between dietary groups in the present study. This is in agreement with Kennelly and Khorasani (1993) who fed whole flaxseed at 0, 5, 10 , or $15 \%$ of DMI without affecting milk yield. Petit (2003), who fed either whole untreated or whole formaldehyde-treated flaxseed or sunflower seed, also found no difference in milk yield among the diets. However, in a later study, milk yield was higher in cows fed flaxseed compared with those fed sunflower seed (Petit et al., 2004). Concentration and yield of milk fat de- 
clined over time in SUNF cows in the present study, whereas they remained unaffected in FLAX cows. Milk fat concentration and yield were not affected by feeding flaxseed at $0,5,10$, or $15 \%$ of the DMI (Kennelly and Khorasani, 1993), or flaxseed and sunflower seed with or without formaldehyde-treatment (Petit, 2003). Even though there was no difference in milk fat concentration and yield between cows fed flaxseed or sunflower seed in the work of Petit et al. (2004), cows fed flaxseed yielded more milk fat $(1.14 \mathrm{~kg} / \mathrm{d})$ compared with those fed a no-fat control diet $(0.85 \mathrm{~kg} / \mathrm{d})$.

Milk protein percentage and yield did not differ between the dietary groups in our study. Petit (2003) reported a higher concentration of milk protein in cows fed flaxseed (3.38\%) compared with those fed sunflower seed (3.21\%) although inclusion of flaxseed in the diet did not change concentration or yield of milk protein in other studies (Kennelly and Khorasani, 1993; Petit et al., 2004).

\section{Milk Fatty Acid Composition}

The decrease in medium-chain fatty acids and increase in LCFA concentrations of milk observed for cows fed FLAX and SUNF is in general agreement with the results reported in several previous studies (Goodridge et al., 2001; Petit, 2003; Petit et al., 2004) of cows fed diets enriched in PUFA. Significant increases occurred in the proportions of both ALA and linoleic acid with both dietary treatments, the most notable being ALA, which nearly tripled on the FLAX diet. The highest concentration of ALA in milk after feeding flaxseed, in most previous studies, was similar to what was seen in the present study. Mean concentrations of ALA usually range from 0.9 to $1.1 \%$ of total fatty acids, although ALA concentrations as high as 3.7 to $6.4 \%$ of total fatty acids have been reported after feeding protected (formaldehyde-treated) flaxseed (Goodridge et al., 2001). Cows fed either FLAX or SUNF in the present study had substantial increases in milk PUFA, implying that sufficient quantities of PUFA present in the oilseeds escaped biohydrogenation in the rumen and ultimately were transferred into milk fat.

\section{Plasma Metabolites}

Dietary treatments did not significantly affect cholesterol, glucose, NEFA, or triglycerides in the present study. However, glucose concentrations were higher in wk 6 than in other weeks, in both FLAX and SUNF groups. Because of the inclusion of oilseeds in the diets, we expected a time-dependent increase in cholesterol as the duration of diets increased, but this did not occur. In a previous study, cows fed Megalac had a greater increase in blood cholesterol than those fed flaxseed (Petit et al., 2001). The authors suggested that the cholesterol-depressing effect of ALA in flaxseed, as reported by Cunnane et al. (1993) in humans, could have contributed to the difference in the rate of increase in blood cholesterol between control (Megalac) and flaxseed-fed cows. Whether ALA depresses cholesterol in cattle remains to be determined.

\section{CONCLUSIONS}

Including flaxseed in the ration of dairy cows increased the diameter of the ovulatory follicle and reduced pregnancy losses. Although these findings add further strength to the concept that dietary fatty acids enhance reproductive processes in cattle, the underlying mechanisms through which an ALA-enriched diet may improve reproductive function remain unclear. Despite the promising nature of the present findings, larger field trials must be undertaken before advocating producers to include flaxseed in dairy rations as a nutritional strategy for improving reproductive performance.

\section{ACKNOWLEDGMENTS}

This research was supported by funds from Alberta Milk, Agriculture and Agri-Food Canada's Matching Investment Initiative, and Alberta Agriculture Food and Rural Development. The authors gratefully acknowledge the contributions of the following agencies and individuals: Pioneer Hi-Bred Limited for donating sunflower seed; Schering Canada Inc. (Animal Health) for donating Estrumate; Vétoquinol Canada for donating Fertiline; Prasanth Chelikani and John Bell for their assistance with fatty acid analysis, and Prasanth Chelikani for his help with statistical analyses; Brian Cameron, Harold Lehman, and other staff at the dairy research unit, University of Alberta, for their excellent cooperation and assistance during this project.

\section{REFERENCES}

Abayasekara, D. R. E., and D. C. Wathes. 1999. Effects of altering dietary fatty acid composition on prostaglandin synthesis and fertility. Prostaglandins Leukot. Essent. Fatty Acids 61:275-287.

Burke, J. M., C. R. Staples, C. A. Risco, R. L. De la Sota, and W. W. Thatcher. 1997. Effect of ruminant grade menhaden fish meal on reproductive and productive performance of lactating dairy cows. J. Dairy Sci. 80:3386-3398.

Chouinard, P. Y., L. Corneau, A. Sæbø, and D. E. Bauman. 1999. Milk yield and composition during abomasal infusion of conjugated linoleic acids in dairy cows. J. Dairy Sci. 82:2737-2745.

Colazo, M. G., J. P. Kastelic, M. F. Martinez, P. R. Whittaker, R. Wilde, J. D. Ambrose, R. Corbett, and R. J. Mapletoft. 2004. Fertility following fixed-time AI in CIDR-treated beef heifers given GnRH or estradiol cypionate and fed diets supplemented with flaxseed or sunflowerseed. Theriogenology 61:1115-1124. 
Cunnane, S. C., S. Ganguli, C. Menard, A. C. Liede, M. J. Hamadeh, Z. Y. Chen, T. M. Wolever, and D. J. Jenkins. 1993. High alphalinolenic acid flaxseed (Linum usitatissimum): Some nutritional properties in humans. Br. J. Nutr. 69:443-453.

Goodridge, J., J. R. Inglais, and G. H. Crow. 2001. Transfer of omega3 linolenic acid and linoleic acid to milk fat from flaxseed or Linola protected with formaldehyde. Can. J. Anim. Sci. 81:525-532.

Gulati, S. K., J. R. Ashes, and T. W. Scott. 1999. Hydrogenation of eicosopentaenoic and docosohexaenoic acids and their incorporation into milk fat. Anim. Feed Sci. Technol. 79:57-64.

Hagemeister, H., D. Precht, M. Franzen, and C. A. Barth. 1991. Alpha-linolenic acid transfer into milk fat and its elongation by cows. Fat Sci. Technol. 93:387-391.

Kassa, T., J. D. Ambrose, A. L. Adams, C. Risco, C. R. Staples, M. J. Thatcher, H. H. Van Horn, A. Garcia, H. H. Head, and W. W. Thatcher. 2002. Effects of whole cottonseed diet and recombinant bovine somatotropin on ovarian follicular dynamics in lactating dairy cows. J. Dairy Sci. 85:2823-2830.

Kaul, V., and B. S. Prakash. 1994. Accuracy of pregnancy/non pregnancy diagnosis in zebu and crossbred cattle and Murrah buffaloes by milk progesterone determination post insemination. Trop. Anim. Health Prod. 26:187-192.

Kennelly, J. J., and G. R. Khorasani. 1993. Influence of flaxseed feeding on fatty acid composition on cows milk. Pages 99-105 in Proc. 54th Flax Inst. Conf., Fargo, ND. J. F. Carter, ed. North Dakota State Univ., Fargo.

Kenward, M. G., and J. H. Roger. 1997. Small sample inference for fixed effects from the restricted maximum likelihood. Biometrics 53:983-997.

Littell, R. C., J. Pendergast, and R. Natarajan. 2000. Tutorial in Biostatistics: Modeling covariance structure in the analysis of repeated measures data. Stat. Med. 19:1793-1819.

National Research Council. 2001. Nutrient Requirements of Dairy Cattle. 7th rev. ed. Natl. Acad. Press, Washington, DC.

Olfert, D. E., B. M. Cross, and A. A. McWilliam, ed. 1993. Pages 3134 in Guide to the care and use of experimental animals. 2nd ed. Vol. 1. Canadian Council on Animal Care, Ottawa, Canada.

Peters, M. W., and J. R. Pursley. 2003. Timing of final GnRH of the Ovsynch protocol affects ovulatory follicle size, subsequent luteal function, and fertility in dairy cows. Theriogenology 60:11971204.
Petit, H. V. 2003. Digestion, milk production, milk composition, and blood composition of dairy cows fed formaldehyde-treated flaxseed or sunflower seed. J. Dairy Sci. 86:2637-2646.

Petit, H. V., R. J. Dewhurst, J. G. Proulx, M. Khalid, W. Haresign, and $\mathrm{H}$. Twagiramungu. 2001. Milk production, milk composition, and reproductive function of dairy cows fed different fats. Can. J. Anim. Sci. 81:263-271.

Petit, H. V., C. Germiquet, and D. Lebel. 2004. Effect of feeding whole, unprocessed sunflower seeds and flaxseed on milk production, milk composition, and prostaglandin secretion in dairy cows. J. Dairy Sci. 87:3889-3898.

Pursley, J. R., M. O. Mee, and M. C. Wiltbank. 1995. Synchronization of ovulation in dairy cows using $\mathrm{PGF}_{2 \alpha}$ and $\mathrm{GnRH}$. Theriogenology 44:915-923.

Robinson, R. S., P. G. A. Pushpakumara, Z. Cheng, A. R. Peters, D. R. E. Abayasekara, and D. C. Wathes. 2002. Effects of dietary polyunsaturated fatty acids on ovarian and uterine function in lactating dairy cows. Reproduction 124:119-131.

SAS Institute. 2000. SAS/STAT User's Guide, Release 8.0. SAS Institute, Inc., Cary, NC.

Staples, C. R., J. M. Burke, and W. W. Thatcher. 1998. Influence of supplemental fats on reproductive tissues and performance of lactating cows. J. Dairy Sci. 81:856-871.

Starbuck, M. J., R. A. Dailey, and E. K. Inskeep. 2004. Factors affecting retention of early pregnancy in dairy cattle. Anim. Reprod. Sci. 84:27-39.

Sukhija, P. S., and D. L. Palmquist. 1988. Rapid method for determination of total fatty acid content and composition of feedstuffs and feces. J. Agric. Food Chem. 36:1202-1206.

Tenhagen, B. A., R. Surholt, M. Wittke, C. Vogel, M. Drillich, and W. Heuwieser. 2004. Use of Ovsynch in dairy herds: Differences between primiparous and multiparous cows. Anim. Reprod. Sci. 81:1-11.

Thatcher, W. W., M. Binelli, J. Burke, C. R. Staples, J. D. Ambrose, and S. Coelho. 1997. Antiluteolytic signals between the conceptus and endometrium. Theriogenology 47:131-140.

Thatcher, W. W., T. Bilby, C. R. Staples, L. MacLaren, and J. Santos. 2004. Effects of polyunsaturated fatty acids on reproductive processes in cattle. Pages 1-28 in Proc. 19th Annu. SW Nutr. Mgmt. Conf., Tempe, AZ. Dept. Anim. Sci., Univ. Arizona, Tucson.

Wildman, E. E., G. M. Jones, P. E. Wagner, R. L. Boman, H. F. Troutt, Jr., and T. N. Lesch. 1982. A dairy cow body condition scoring system and its relationship to selected production characteristics. J. Dairy Sci. 65:495-501. 